\section{RHINOLOGY: DISEASES OF THE NOSE, SINUSES, AND SKULL BASE}

D W Kennedy, P H Hwang, eds

Thieme Medical Publishers, 2012

ISBN 9781604060607 pp 800 Price $€ 189.99$ \$US229.99

This typically handsome Thieme publication is a comprehensive, hardback textbook of rhinology. Edited by two very well respected rhinologists, with the support of 130 international contributors, it is a superb presentation of all aspects of this sub-specialty.

The glossy pages with colour diagrams, clinical photos and imaging pictures complement the text. The 800 pages are divided into 54 chapters covering anatomy, physiology, and medical and surgical aspects of sinonasal and skull base disease. As this is a book on 'diseases', do not look for chapters on aesthetic rhinoplasty; there are many other books out there covering this topic.

Each chapter is written in a systematic and easy to read fashion, culminating in a conclusion section and references. Details of surgical technique are supplemented by an accompanying DVD which contains some excellent surgical videos of procedures. This DVD in itself is a very well produced, high quality, 'how I do it' style summary with a clear running narrative during the videos.

One minor omission is the absence of bullet-point boxes, favoured by many current publishers, which allow for an 'at a glance' summary of a chapter.

However, overall, this is a fine textbook which will be of value to practising rhinologists and trainees

\section{Rhinology}

\section{Diseases of the Nose, Sinuses, and Skull Base}

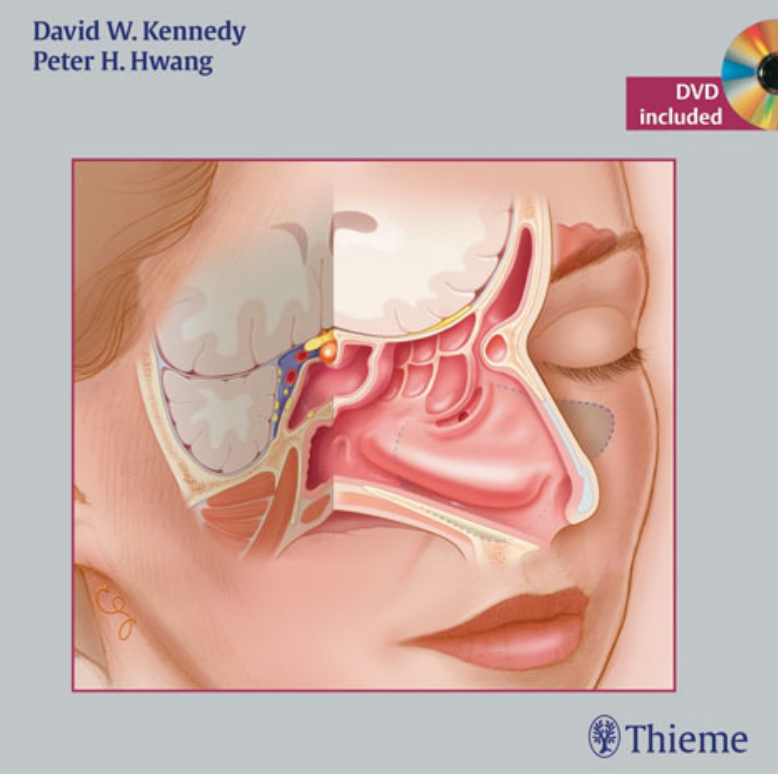

alike. The latter will gain great benefit from the DVD, with its clear demonstrations of surgical techniques

The Journal of Laryngology \& Otology (2012), 126, 1194.

(c) JLO (1984) Limited, 2012

doi:10.1017/S0022215112002307

\title{
Osteocartilaginous choristoma: a case report - CORRIGENDUM
}

A ROPER, D SUBAR, B BENITAR, A E R KOBBE

doi:10.1017/S002221510600199X, Published by Cambridge University Press, July 2006, page e23.

This paper $^{1}$ was published online only. In this publication, the third author's name was shown as:

B Benitar

This name should read:

B Benatar

Reference

1 Roper A, Subar D, Benitar B, Kobbe AER. Osteocartilaginous choristoma: a case report. J Laryngol Otol 2006;120:e23 